This document was prepared in conjunction with work accomplished under Contract No. DE-AC09-96SR18500 with the U.S. Department of Energy.

This work was prepared under an agreement with and funded by the U.S. Government. Neither the U. S. Government or its employees, nor any of its contractors, subcontractors or their employees, makes any express or implied: 1 . warranty or assumes any legal liability for the accuracy, completeness, or for the use or results of such use of any information, product, or process disclosed; or 2 . representation that such use or results of such use would not infringe privately owned rights; or 3 . endorsement or recommendation of any specifically identified commercial product, process, or service. Any views and opinions of authors expressed in this work do not necessarily state or reflect those of the United States Government, or its contractors, or subcontractors. 
WSRC-STI-2007-00370

\title{
Traditional Metallurgy, Nanotechnologies and Structural Materials: A Sorby Award Lecture
}

\author{
M. R. Louthan, Jr. \\ Materials Science \& Technology \\ Savannah River National Laboratory \\ Aiken, SC 29808
}

\begin{abstract}
Traditional metallurgical processes are among the many "old fashion" practices that use nanoparticles to control the behavior of materials. Many of these practices were developed long before microscopy could resolve nanoscale features, yet the practitioners learned to manipulate and control microstructural elements that they could neither see nor identify. Furthermore, these early practitioners used that control to modify microstructures and develop desired material properties. Centuries old colored glass, ancient high strength steels and medieval organ pipes derived many of their desirable features through control of nanoparticles in their microstructures. Henry Sorby was among the first to recognize that the properties of rocks, minerals, metals and organic materials were controlled by microstructure. However, Mr. Sorby was accused of the folly of trying to study mountains with a microscope. Although he could not resolve nanoscale microstructural features, Mr. Sorby's observations revolutionized the study of materials.
\end{abstract}

The importance of nanoscale microstructural elements should be emphasized, however, because the present foundation for structural materials was built by manipulating those features. That foundation currently supports several multibillion dollar industries but is not generally considered when the nanomaterials revolution is discussed. This lecture demonstrates that using nanotechnologies to control the behavior of metallic materials is almost as old as the practice of metallurgy and that many of the emergent nanomaterials technologists are walking along pathways previously paved by traditional metallurgists.

\section{Introduction}

I am greatly honored to receive the Sorby Award. Henry C Sorby has been called the last great amateur scientist for his contributions to geology, metallurgy, microscopy and biology. He also studied architecture, old churches, medieval art and hieroglyphics and painted in water colors. He was rich, independent and never studied at a university because he wanted an education that prepared him for a career as an original investigator not an education designed to prepare him to pass an examination. He certainly would have thought that many of today's educational schemes are badly flawed. Mr. Sorby studied mountains with a microscope, choose to live in his home town of Sheffield rather than moving to the center of science in London and felt that discovery was its own reward. Science and engineering needs more investigators like Henry Clifton Sorby and fewer investigators that probe primarily for personal profit. 
Henry Sorby recognized that the properties of rocks, minerals, metals and even organic materials were controlled by microscopic features. Had the tools been available, Mr. Sorby would surely have probed deeply into materials structure and sub-structure and the now in vogue term "nanotechnology" would be over 100 years old.

There is significant potential for dramatic improvement in the properties of structural metals and alloys. Much of that improvement will come through the application of nanotechnologies to the practice of traditional metallurgy and some improvement may come through the use of nanowires, nanotubes and other modern nanoparticles. However, current research funding practices transfer resources previously used to fund research in traditional metallurgy to programs that investigate emergent nanomaterials. This transfer, at best delays, and may even mitigate the potential for the near-term development of new high quality, reliable structural materials.

Nanotechnologies are technologies that deal with materials, devices and systems that have fundamentally new properties because their structures have one or more length scales in the range of 1 to 100 nanometers. This length scale represents the transition from single atoms to bulk materials. The characteristics of materials can change significantly when the length scale is reduced, particularly when the scales are reduced to the 10 to $20 \mathrm{~nm}$ range (1).

There are estimates that the impact of nanotechnologies may exceed the impact of the Industrial Revolution (2). Such an impact is anticipated because of the novel physical, chemical and biological properties obtained in nanomaterials. These properties have lead to increasing industry and government investment in nanotechnology research.

Worldwide government investment rose from $\$ 430$ million per year in 1997 to just under $\$ 3$ billion per year in 2003 (3) and has continued to increase. Although much of the current nanomaterials research focuses on chemical processing, information technology and electronics, research efforts in traditional metallurgy have been impacted by nanomaterial induced funding swings. These swings have resulted in the transfer of fundamental materials research endeavors from Materials Science and Engineering Departments into Chemistry and Physics Departments. Research funding in the materials arena is almost always a zero sum game thus enhanced funding in one area equates to reduced funding in another. To assure that the funding critical to structural materials development is not lost, the traditional metallurgists should become key players in the nanotechnology revolution. Additionally, as the gate keepers of materials technology, universities must assure that a substantial fraction of their materials research is associated with technologies that will provide improved materials for emergent engineering applications.

Control of nanostructures has been a key to many metallurgical processes for over a century and the new emphasis in this materials arena should be used by metallurgists to build from those early processes. New technologies generally build upon the foundations laid by previous work and although they may not have championed nanotechnologies, the traditional metallurgist use nanotechnologies to improve their metals and alloys. 
Metallurgist routinely engineer nanoparticles to control the properties of both ferrous and non-ferrous alloys. Although this fact is well known, the traditional metallurgy community has found it difficult to capitalize on the nanomaterials revolution. Processes such as age hardening, tempering and alloying to control corrosion resistance all involve metallurgical processes which could be termed nanotechnologies. For example, the $\gamma$ ' precipitates that increase the strength of some nickel based super alloys are less than 100 $\mathrm{nm}$ in diameter, carbide particles in some tempered steels are 10's of $\mathrm{nm}$ in diameter and the thickness of the protective films on many corrosion resistant alloys is in the $100 \mathrm{~nm}$ range. However, research in these well established, milti-billion dollar material arenas has not benefited and may even have been diminished by the nanotechnology revolution. Traditional metallurgy needs a new "Henry Sorby" to champion the fact that the properties of structural materials are controlled by microscopic features that have length scales in the 1 to 100 nanometer range. This observation indicates that the metallurgical could expertise in controlling nanoparticles in structural materials should be used to obtain some of the resources designated for research in the nanotechnology revolution. The manipulation of nanoparticles will be used to develop new alloys which have properties tailored to meet emergent industrial requirements just as nanotechnologies were previously used to develop many of the currently available structural materials.

\section{Size, Strength and Theory}

The huge impact of size on the strength of iron, silver and copper wires was widely recognized over fifty years ago when Brenner published the classic paper "Tensile Strength of Whiskers" in the Journal of Applied Physics (4). Although no nanoscale wires were tested, Brenner showed that the average strength of iron whiskers (fabricated by his processes) was given by

$$
\sigma=(1630 / \mathrm{d}-50) \mathrm{kg} / \mathrm{mm}^{2}
$$

where $\mathrm{d}$ is the diameter of the whisker in $\mu \mathrm{m}$. This equation predicts that the theoretical strength of iron would be obtained in a whisker with a diameter of $700 \mathrm{~nm}$ or less. The data used to develop this equation are summarized graphically in Figure 1.

The theoretical strength of an isotropic crystalline solid is roughly one tenth of its Young's modulus. Therefore the theoretical strength of an iron whisker is approximately $3,000,000$ psi. Based on this value, the tensile strength that Brenner obtained in $2 \mu \mathrm{m}$ diameter whiskers in 1956 was about $60 \%$ of the theoretical strength of iron. This is an interesting number because the claim is often made that carbon nanotubes have strength levels 100 times that of steel. However, the theoretical strength of carbon nanotubes is roughly only seven higher than the theoretical strength of iron. Thus, it appears unlikely that a carbon nanotube can obtain a strength level that exceeds the strength of Brenner's fifty year old iron whiskers by much more than a factor ten.

The affects of whisker diameter on strength were attributed to the presence and orientation of defects in the whiskers. Brenner states that "the strengths of the perfect whiskers must be decreased by defects which are distributed statistically in a rather 
complex manner" and assumes that "the defects are introduced accidentally during growth" (4). He also showed that "just prior to fracture the (copper) whiskers would suddenly yield at one or more points with the appearance of slip lines which were easily visible on the highly reflectant whisker surface". The defects responsible for the variable strength in the whiskers include dislocations and surface irregularities. Although the presence of such defects may be minimized through careful processing, "it was recognized decades ago that it is unwise to rely on perfection as a method of designing strong materials" (5).

Material technologies that achieve high strengths by relying on perfection "necessarily fail on scaling to engineering dimensions" (5), thus from a practical standpoint structural engineers should not rely on materials that obtain strength through perfection. The applicability of this fact to carbon nanotubes is illustrated in Table 1 which shows that the measured strength of carbon nanotube based ropes decreases rapidly with increasing nanotube length. The data in Table 1 are the basis for a conclusion that "there is no carbon tube that can match the strength of iron beyond a scale of $2 \mathrm{~mm}$ " (5). Scaling difficulties and other inherent problems with perfection are the primary reasons that high strength structural materials have not evolved from whisker technology even though over fifty years have passed since high strength whiskers were first fabricated. However, the lure of perfection is strong. For example, embedded atom techniques have been used to demonstrate that even the theoretical strength of metals is size dependent (6) and that this theoretical strength increases as the size decreases. This size affect on theoretical strength is ascribed to the enhanced attraction between atoms because of electron charge redistribution near the surfaces of nanowires. However, transfer of size and perfection effects from nanowires wires to structural components is, at best, somewhere in the future while traditional metallurgical practices can use nanotechnologies to achieve high strength structural materials today..

Traditional metallurgy has long recognized that perfection is difficult to achieve in structural materials and virtually all the high strength, structural metals and alloys were developed by controlling the microstructural defects. Metallurgists have also recognized that engineered structures require flaw tolerant materials. Attempts to eliminate defects and obtain perfection in structural systems have generally been unsuccessful and flaw tolerance is necessary in many engineering applications. Many of the microstructural defects that are controlled by traditional practices meet the size requirements for nanotechnologies. These traditional techniques are so old that they appear routine and may not attract a researcher seeking to investigate cutting edge science. However, the fundamental and applied research programs that investigate the control of nanoscale microstructural defects in emergent metallic systems will, for at least another decade, provide the vast majority of the new structural metals used for large scale civil and engineering systems.

\section{Traditional Strengthening Technologies}

The microstructural defects primarily responsible for the low strength of reasonably pure metals are dislocations. Dislocation motion (slip) takes place at stress levels far below the 
theoretical strength of pure metals. For example, the shear stress necessary to cause dislocation motion (plastic flow) in a magnesium single crystal is approximately $100 \mathrm{psi}$ while the theoretical shear strength of magnesium is approximately $1,000,000 \mathrm{psi}$ or 10,000 times higher than the measured strength (7). Dislocations move at such low stresses because their configuration allows slip to occur locally rather than globally. When slip is localized only the atoms near the dislocation core are displaced and slip progresses as the dislocation moves across the slip plane. Thus, the presence of dislocations in metals eliminates the simultaneous displacement of a whole plane of atoms and causes the actual strength to be significantly lower than the theoretical strength. Dislocations are line defects and although the diameter of the dislocation is difficult to establish exactly, a size scale of one to ten $\mathrm{nm}$ provides a realistic approximation. Traditional strengthening mechanisms for metals involve impeding or mitigating dislocation motion. Thus, traditional metallurgy practices increase the strength of metals and alloys by controlling the behavior of nanosize configurations in the microstructure.

Techniques to mitigate dislocation motion include solid solution strengthening and work hardening. Solid solution strengthening involves interaction of solute atoms with dislocations while work hardening simply involves the interaction of dislocations with other dislocations. The strengthening obtained by solid solution hardening and work hardening is illustrated in Figures 2 and 3 respectively. Both types of interactions impede dislocation motion, thus when the Bronze Age metallurgist added tin to copper and then hammered (cold worked) the resulting bronze alloy into the desired shape, nanotechnologies were being used. These early nanotechnologists, like those of today, used their skills to develop implements for war and to produce the fine, new products required for better living. I'm reasonably certain that if today's analytical tools had been available to Henry Sorby the $20^{\text {th }}$ century understanding of strengthening mechanisms in metals would have developed in the 1800s. Mr. Sorby was convinced that tiny, microscopic defects played major roles in materials behavior and used the available instruments to examine microstructure. However, even without the ability to observe nanoscale objects, the foundation for understanding the strengthening mechanisms in metals and alloys was laid in the 1930's (8).

Metallurgists also demonstrated that high strengths could attained by controlling solid state reactions in various alloys. For example, small amounts of columbium, vanadium, copper, titanium and aluminum were found to significantly increase the strength of steels. The concentration of these alloys in the high strength low alloy steels is too low (usually less than $0.15 \%$ ) to cause significant solution hardening (copper is an exception to this statement) and strengthening takes place by the formation of precipitates. Several important strengthening precipitates in the HSLA steel are outlined in Table II. These alloy elements are dissolved in the steels at the ingot or slab soaking temperatures and the precipitates form during hot rolling operations. To obtain the maximum strengthen in these alloys, the steels are also given a solution anneal, quenched and aged at an intermediate temperature for a suitable time. Early work with HSLA steels revealed that precipitate-dislocation interactions were responsible for the strength increases and that strengthening effect depended primarily on the precipitate distribution. This distribution 
depends the distance between precipitates which, in turn, depends on the number of precipitates. Therefore, for a given amount of precipitate in the alloy, the smaller the precipitates the greater the number, the closer the spacing and the greater the strengthening effect. By the 1970's the importance of nanoprecipitates was widely recognized (9). Figure 4, taken from Fletcher's book on HSLA steels (9), demonstrates that columbium carbide precipitates in a $2000 \mathrm{~nm}$ diameter range had little effect on the strength while $10 \mathrm{~nm}$ diameter particles significantly increased the strength. The addition of only $0.06 \%$ columbium to steel increased the strength by almost $30,000 \mathrm{psi}$ if the precipitate size was controlled to $1 \mathrm{~nm}$ while the strength of the same alloy was only increased by $2,000 \mathrm{psi}$ if the precipitates were allowed to grow to $20 \mathrm{~nm}$ in diameter. Processing to control precipitate size in the nanometer range is a long established, routinely used, traditional metallurgical practice.

Production and use of copper-beryllium, 2000 series aluminum alloys and age hardenable nickel based super alloys requires the control of nanoscale precipitates. Each of these alloy systems contributes billions of dollars annually to the worldwide economy. The success of each of these industries is due to the development of industrial practices that control the size, shape and distribution of nanoprecipitates. Alloy chemistry and thermomechanical processes are varied to produce alloys with properties tailored for specific applications. Additionally, most alloy systems have the potential for significant future improvements in strength that may be achieved through changes in the alloy chemistry and processing practices. Successful development of the next generation alloy systems will hinge on applied and fundamental research directed toward the control of nanoprecipitates and other nanoscale features in the alloys.

\section{Degradation of Metals and Alloys}

Nanoscale interactions can lead to the degradation of metals and alloys and well as to the creation of desirable mechanical properties. For example, sensitization of austenitic stainless steel weldments involves chromium depletion near grain boundaries in the weld heat affected zones. The width of the chromium depleted region will depend on the time/temperature profile, the carbon content and the concentration of other alloy/impurity elements. However, measurements on Type 304 stainless steel show that the chrome depletion may occur in a zone less than $100 \mathrm{~nm}$ on either side of the grain boundary, Figure 5 (10). The chromium depleted region develops because the time- temperatures profile experienced by the alloy causes chrome rich carbide precipitation at the grain boundaries. The chromium that forms the grain boundary carbides comes almost entirely from the near grain boundary region while the carbon for the carbides can come from throughout the grain because carbon diffuses much faster than chromium. Long before the analytical tools were available to evaluate the chromium depleted region, traditional metallurgists learned to mitigate the tendency for chromium depletion by either reducing the carbon content (Type 304L stainless steel), adding an element to react with carbon and minimize its interaction with chromium (Type 347 stainless steel) or requiring the use of special annealing treatments. Thus, although they could not directly determine chemistry at a nanoscale level, the traditional metallurgist prevented deleterious 
nanoscale interactions by careful attention to alloy chemistry and heat treatment procedures.

Pitting, stress corrosion cracking and other local corrosion processes frequently initiate at nanoscale surface defects. For example, slip step emergence can rupture passive films on metal surfaces, Figure 6, and expose the underlying, non-passivated metal to the environment. The exposed metal may become the anode in an electrochemical cell and serve as an initiation site for localized corrosion. Continuation of this highly localization corrosion process may lead to macroscopic pitting (pits need to be approximately $20 \mu \mathrm{m}$ in diameter to be stable) or stress corrosion cracking. Slip step height and hence the amount of exposed metal depends on the stacking fault energy of the alloy. Deformation of low stacking fault energy materials produces coarse slip while similar deformations in high stacking energy materials produce fine slip. Low stacking fault energy alloys tend to be more susceptible to stress corrosion cracking than high stacking fault energy alloys (11) as is consistent with slip step emergence causing rupture of the passive film. Slip steps, stacking faults and passive films are all nanoscale features in/on the crystal lattice and by controlling these features one can change the material's susceptibility to localized corrosion processes.

High cycle fatigue striations and direct measurements of crack growth rates (Figure 7) (12) demonstrate that the length scales for crack growth per cycle can be well within the nanoscale range. Although fatigue remains a major cause of unanticipated failures in industrial systems, traditional metallurgy has provided a basis for significant reductions in the susceptibility of metals and alloys to fatigue. Further reductions will be accomplished as the nanoscale interactions occurring adjacent to the fatigue crack tip become better understood.

Corrosion is another materials degradation process that involves interactions on the nanoscale level. The ASM International's Materials Handbook (13) states that aluminum owes "its usage as one of the primary metals of commerce to the barrier oxide film that is bonded strongly to its surface and that, if damaged reforms immediately in most environments". The thickness of this barrier film is only $1 \mathrm{~nm}$ when the film is formed on a freshly abraded aluminum surface exposed to room temperature air. The thickness may be one to two orders of magnitude greater when the film forms in more aggressive environments. The process of corrosion requires penetration of this barrier oxide. Alloy additions, in solution and precipitated as submicroscopic particles (nanoscale dimensions), are selected because of their impacts on both the strength and penetrability of this nanoscale thick barrier film. Furthermore, understanding and controlling the chemistry, thickness and behavior of such protective films is fundamental to achieving advancements in corrosion resistant metals and alloys.

Corrosion and fatigue processes are major causes of industrial failures that cost the economy tens of billions of dollars each year. Prevention of even a small percentage of that loss through advancements in material's technology would represent a significant achievement. Such achievements should be possible if the traditional metallurgists apply 
the emergent analytical tools to probe the nanoscale structure of metals and develop alloys that resist the nanoscale interactions involved in these degradation processes.

\section{Traditional Metallurgy, Nanoparticles and the Relatively Recent Literature}

One of the basic reasons that the world is embracing the nanotechnology revolution is clearly expressed as a goal of the National Nanotechnology Initiatives. The initiative is to "create new jobs and enhance industrial competitiveness" (14). A glance at the recent materials engineering and science literature demonstrates the wide spread industrial application of nanotechnologies by the traditional metallurgists. By controlling the formation of nanoparticles in various alloys, researchers have increased material toughness $(15,16)$, strength $(16,17)$ and creep (18) and fatigue (16) resistance, improved age hardening kinetics $(17,19)$, increased the quality of hot-isostatically pressed super alloys (20), improved the mechanical properties of cast alloys (21), developed superior shape memory characteristics (22), increased the work hardening rates (23) and induced superplasticity (24).

These nanoparticle effects were induced in a variety of ways. Titanium additions to microalloyed steels increased the toughness of the steel because the formation of nanoscale, cruciform precipitates removed nitrogen, vanadium and niobium that ordinarily would have precipitated in ferrite as dispersion hardening particles and kept the material toughness low (15). Nanosized (15 nm) dispersoids of $\mathrm{Al}_{7} \mathrm{Cr}$ played a major role in pinning subboundaries thus allowing superplasticity to occur in an Al-Mg-Mn alloy (24) while boron additions to Type 347 stainless steels caused enhanced the precipitation of carbonitrides and nanosized borides which increased the creep strength (18) by inhibiting grain boundary sliding. The precipitation of "dense and fine $\mathrm{Ti}_{3} \mathrm{Ni}_{4}$ precipitates with a size below $10 \mathrm{~nm}$ caused superior shape memory characteristics to appear" in a titanium-nickel alloy (22) because of the precipitates impact on the martensite transformation.

Nanosized precipitates in an aluminum copper alloy were impenetrable obstacles to dislocations, thus increasing the work hardening characteristics of the material (23). The addition of cerium (up to $0.45 \%$ ) to an $\mathrm{Al}-\mathrm{Cu}-\mathrm{Mg}-\mathrm{Ag}$ alloy refined the grains and induced a fine uniform distribution of both shearable and non-shearable nano-sized precipitates and provided a balanced set of mechanical properties (21). The addition of $0.1 \% \mathrm{Zr}$ to $\mathrm{Cu}-\mathrm{Ti}$ alloys altered the precipitation hardening characteristics promoting the formation of $\mathrm{Cu}_{4} \mathrm{Ti}$ during aging and the formation of $\mathrm{Cu}_{3} \mathrm{Ti}$ during over aging rather than the formation discontinuous precipitates (17). These positive impacts of nanoparticles on materials behavior demonstrate that nanotechnologies play a significant role in alloy development. One task that the metallurgist should welcome is that of fully integrating traditional metallurgical practices into the nanotechnology revolution. However, this integration will not occur unless the importance of nanoscale microstructural elements to materials behavior is fully embraced by the metallurgical community. 


\section{Allocation of Resources for Research}

The evolution of traditional metallurgical practices to produce improved metallic alloys will, at least for the next decade, depend on the control of nanoscale microstructural features. The case for this conclusion is built upon the fact that previous advancements in metallurgy have often depended on similar microstructural control. However, there is a major difference today. Analytical tools provide high resolution views of material microstructure and local chemistry. Atomistic models are available to probe the behaviors of engineered alloys, predict mechanical properties and estimate corrosion resistance. Materials testing platforms can readily assess the performance of newly developed alloys and there is a well defined need for stronger, tougher and cheaper materials for use at ever increasing temperatures and in highly aggressive environments. Traditional metallurgy is addressing these and other material challenges and because progress in those arenas requires control of nanoscale features, metallurgy should be the prince charming of the materials component of the nanotechnology revolution. Unfortunately, the traditional metallurgist has not moved in this direction and research funding to address traditional metallurgical challenges is being diluted, rather than enhanced, by the revolution. This dilution is occurring even though the development of significant improvements in the properties of metals and alloys will obviously "create new jobs and enhance industrial competitiveness" thus satisfying a major goal of the National Nanotechnology Initiatives.

Large increases in government investments in one arena are typically funded by corresponding decreases in other, often related, areas. In this case, the increase in funding for nanomaterial research was accompanied by decreases in funding for research related to traditional metallurgy practices, especially in the structural materials arena. Nanotechnology initiatives are national topics within the world community but few of these initiatives intentionally interface with traditional metallurgy practices. The traditional metallurgist must work to change this situation. Currently the nanotechnology revolution is draining research oriented resources from traditional metallurgy because nanotechnologies are considered new and funds designated for nanotechnology research are not being directed toward traditional metallurgical practices. Additionally, fundamental research into the corrosion of passive metals and alloys (aluminum, stainless steels, titanium, zirconium, etc.) has been reduced as funding for the nanotechnology revolution has increased.

Today's structural materials evolved from metallurgical practices that modified imperfect, flaw tolerant metals by controlling the size, shape and distribution of nanoscale features in the microstructure. Many of these control technologies were developed before the tools were available to actually observe the features being controlled. Now that the analytical tools are available, the metallurgist should engage the nanotechnology revolution and demonstrate that developing new high strength, high temperature, materials is achievable by controlling nanoscale features in metals and alloys. 
The assembly of nanoparticles to create structural materials provides a scaling challenge that is not relevant to traditional metallurgical practices. Building structural metals and alloys from nanoscale particles involves attaching the particles together in some fashion and past results suggest that such scaling is extremely difficult and may even be impractical. However, the practicality of creating new materials by controlling the microstructure at a nanoscale level through traditional metallurgy practices has been fully demonstrated on numerous structural materials. Additionally, now that analytical tools to assess the metallurgy and chemistry of nanoscale microstructural elements are readily available, traditional metallurgy should be uniquely positioned to develop the next generation of structural materials.

\section{Closing Thoughts}

Henry C. Sorby supported his own research and through that research obtained the information necessary to show that slates will form cleavage lines in directions unrelated to the way in which they were originally deposited. His observations flew in the face of the conventional wisdom and well positioned scientists suggested that he should stop his investigations. Fortunately, he ignored their advice and ultimately his work initiated a revolution in the understanding of material's behaviors. The improvements in microscopes over the last one hundred years now provide the traditional metallurgist with the ability study atoms, alloys and the details of crystalline and non-crystalline structures. Tools are even available to manipulate atoms on a crystal lattice. This ability enhances understanding and provides the foundation for large scale improvements in the behaviors of metallic systems. Part of this foundation was envisioned by Feynman in the classic paper "There's Plenty of Room at the Bottom" (25). Unfortunately, fundamental research is expensive and there are few, if any, scientists who can afford to support their own research interests. Consequently, much of the current fundamental research is supported by governments. Governmental spending for materials research is relatively constant from one year to the next, thus, when the funding for one research initiative increases, the funding for another initiatives decreases. In the current situtation, as funding for investigations of carbon nanotubes, metallic nanowires, nanocomposite coatings and other nanomaterials technologies has increased, the funding for more traditional metallurgical research has decreased. I'm convinced that if Henry Sorby were to speak to today's metallurgical community, he would emphasize the need to use the emerging analytical tools to improve traditional metallurgical practices. There are some well positioned scientists who, through their funding practices, are suggesting that traditional metallurgical investigations should step aside from the nanotechnology revolution. However, the traditional metallurgist has been applying nanotechnologies to successful commercial endeavors for over a century and, since "there is plenty of room at the bottom (25)", why should traditional research be slowed simply because a revolution is taking place? 


\section{References}

1) O. Rean and M. C. Roca "Nanotechnology and the Need for Risk Governance", J. Nanoparticle Research, Vol 8(2), p. 2006, Prespectives, Springer Science, Preprint

2) A. Nel, T. Xia, L. Madler and N. Li, "Toxic Potential of Materials at the Nanolevel”, Science, Vol. 311, p. 622, 3 Feb. 2006

3) "Interim Guideline for Working Safely with Nanomaterials" Texas A\&M University, contact bree@tamu.edu, 2006

4) S. S. Brenner, "Tensile Strength of Whiskers", JAP, Vol 27, p. 1484, 1956

5) H. K. D. H. Bhadeshia, " $52{ }^{\text {nd }}$ Hatfield Memorial Lecture: Large Hunks of Very Strong Steel", Materials Science \& Technology, Vol 21, 2005

6) F. Ma and K. W. Xu, "Size -Dependent Theoretical Tensile Strength and Other Mechanical Properties of [001] Oriented Au, Ag and Cu Nanowires", p. 2810, Journal of Materials Research, Vol 21, 2006

7) R. E. Reed-Hill, Physical Metallurgy Principles, Second Edition, p. 144-146, D. Van Norstand Company, New York, 1973

8) E. Orowan, Z. Phys., Vol 89, p. 634, 1934

9) E. E. Fletcher, High Strength Low Allow Steels, p. 125-129, Battelle Press, Columbus, OH, 1979

10) R. K. Dayal, N. Parvathavarthini and B. Raj, "Influence of Metallurgical Variables on Sensitization Kinetics in Austenitic Stainless Steels", International Materials Reviews, 2005

11) R. M. Latanison and R. W. Staehle, "Stress Corrosion Cracking of Iron, Chromium, Nickel Alloys", p 214, Fundamental Aspects of Stress Corrosion Cracking, NACE, Houston, TX, 1969

12) H. Mayer, Fatigue Crack Growth and Threshold Measurements at Very High Frequencies" p 1, International Materials Reviews, Vol 44(1), 1999

13) E. H. Hollingsworth and H. Y. Hunsicker, "Corrosion of Aluminum and Aluminum Alloys”, p 583, Ninth Edition, Metals Handbook, Volume 13 Corrosion, 1987

14) W. J. Madia, "Building the Future on Atom at a Time: Realizing Feynman's Vision", Met. And Matl. Trans. A, p. 2905, Vol. 37A, 2006

15) T. N. Baker, Y. Li, J. A. Wilson, A. J. Crave and D. N. Crowther, "Evolution of Precipitates, in Particular Cruciform and Cuboid Precipitates, During Simulated Direct Charging of Thin Slab Cast Vanadium Microalloyed Steel”, Materials Science and Technology, p. 720, Vol. 20, 2004

16) L. Lasa and J. M. Rodriquez-Ibabe, "Toughness and Fatigue Behavior of Eutectic and Hypereutectic Al-Si-Cu-Mg Alloys Produced Through Lost Foam and Squeeze Casting", Materials Science and Technology, p. 1599, Vol. 20, 2004

17) R. Markandeyer, S. Nagarjuna and D. S. Sarma, "Precipitation Hardening of CuTi-Zr Alloys", Materials Science and Technology, p. 849, Vol. 20, 2004

18) K. Laha, J. Kyona, T. Sasaki, S. Kishinoto and N. Shinyu, "Improved Creep Strength and Ductility of Type 347 Austenitic Stainless Steel Through the Self Healing Effect of Boron on Creep Cavities", Met. and Matl. Trans A, P. 399, Vol. 36A, 2005 
19) V. Beaubois, J. Huez, S. Coste, O. Brucelle and J. Lacaze, "Short Term Precipitation Kinetics of Delta Phase in Strain Free Inconel 718 Alloy", Materials Science and Technology, p. 1019, Vol. 20, 2004

20) G. A. Rao, M. Srinivan and D. S. Sarma, "Effect of Solution Treatment Temperature on Microstructure and Mechanical Properties of Hot Isostatically Pressed Superalloy Inconel 718”, Materials Science and Technology, p. 1161, Vol. 20, 2004

21) D. H. Xiao, J. N. Wang and D. Y. Ding, "Effect of Minor Cerium Additions on Microstructure and Mechanical Properties of Cast Al-Cu-Mg-Ag Alloy", Materials Science and Technology, p. 1237, Vol. 20, 2004

22) J. I. L. Kim and S. Miyazaki, Comparison of Shape Memory Characteristics of a Ti-50.9At. Pct. Ni Alloy aged at 473 and 673 K", Met. and Matl. Trans. A, p.3301, Vol. 36A, 2005

23) H. Sehitoglu, T. Foglesong and H. J. Maier, "Precipitate Effects on the Mechanical Behavior of Aluminum Copper Alloys: Part I. Experiments", Met. and Matl. Trans. A, p. 749, Vol. 36A, 2005

24) S. W. Lee and J. W. Yeh, "Microstructural Evolution and Superplasticity of Al5.8 Mg- 0.23 Mn Alloys Processed by Reciprocating Extrusion”, Met. and Matl. Trans. A, p. 2225, Vol. 36A, 2005

25) H. Feynman, “There's Plenty of Room at the Bottom”, Eng. Sci., p. 22-36, Vol. $23(5), 1960$

List of Figures

1) Effect of Size on the Average Strength of Iron Whiskers

2) Solid Solution Strengthening by the Alloying Copper with Nickel

3) Working Hardening of Low Carbon Steel

4) Effect of Precipitate Size on Strengthening

5) Chromium Depletion in the Near Grain Boundary Region of a Sensitized Steel

6) Schematic of Slip Step Emergence and Passive Film Rupture

7) Crack Growth Rates of a Fatigue Crack

List of Tables

I) Size Effects on the Strength of Carbon Nanotubes

II) Important Strengthening Precipitates in HSLA Steels 


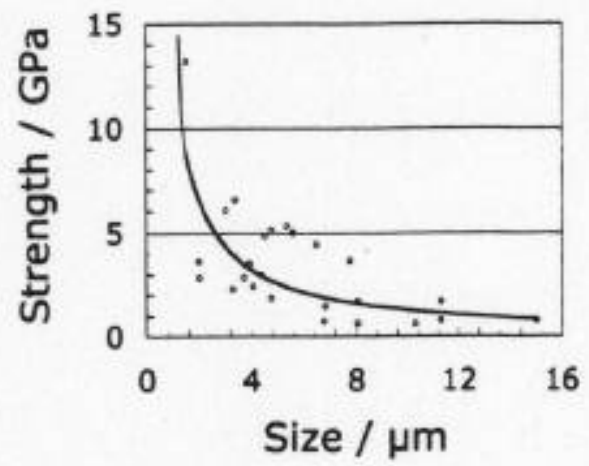

Figure 1 Effect of Size on the Average Strength of Iron Whiskers (5)

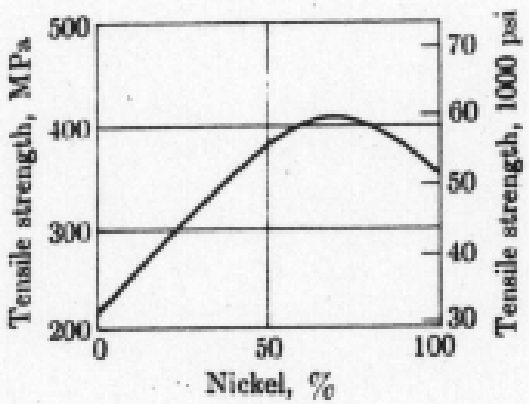

(a)

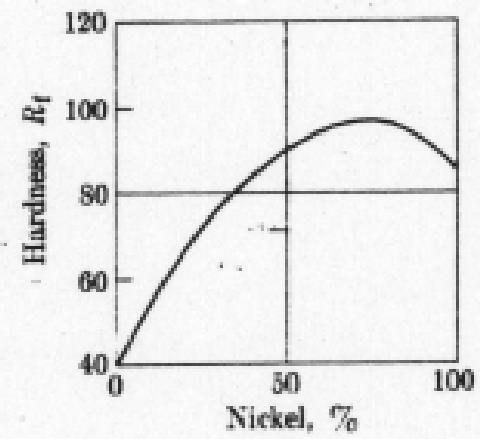

(c)

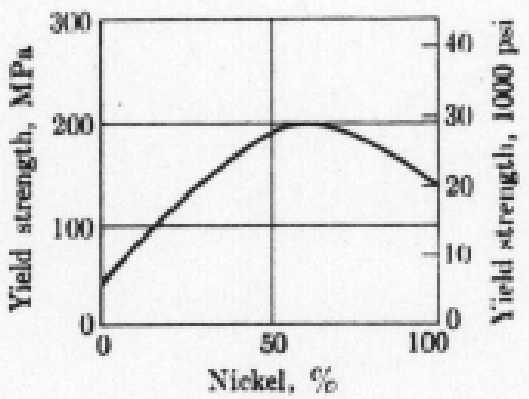

(b)

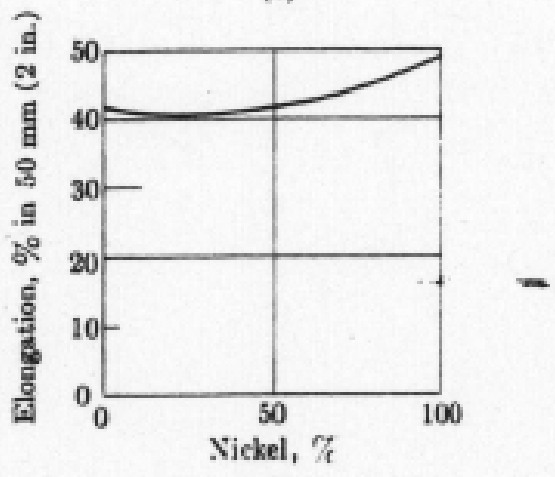

(d)

Figure 2 Solid Solution Strengthening by the Alloying Copper with Nickel 


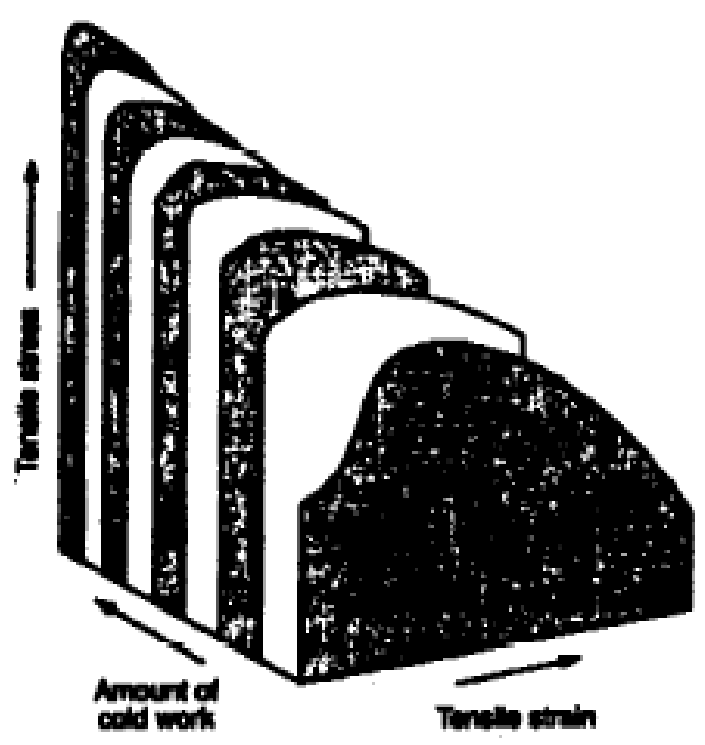

Figure 3 Working Hardening of Low Carbon Steel

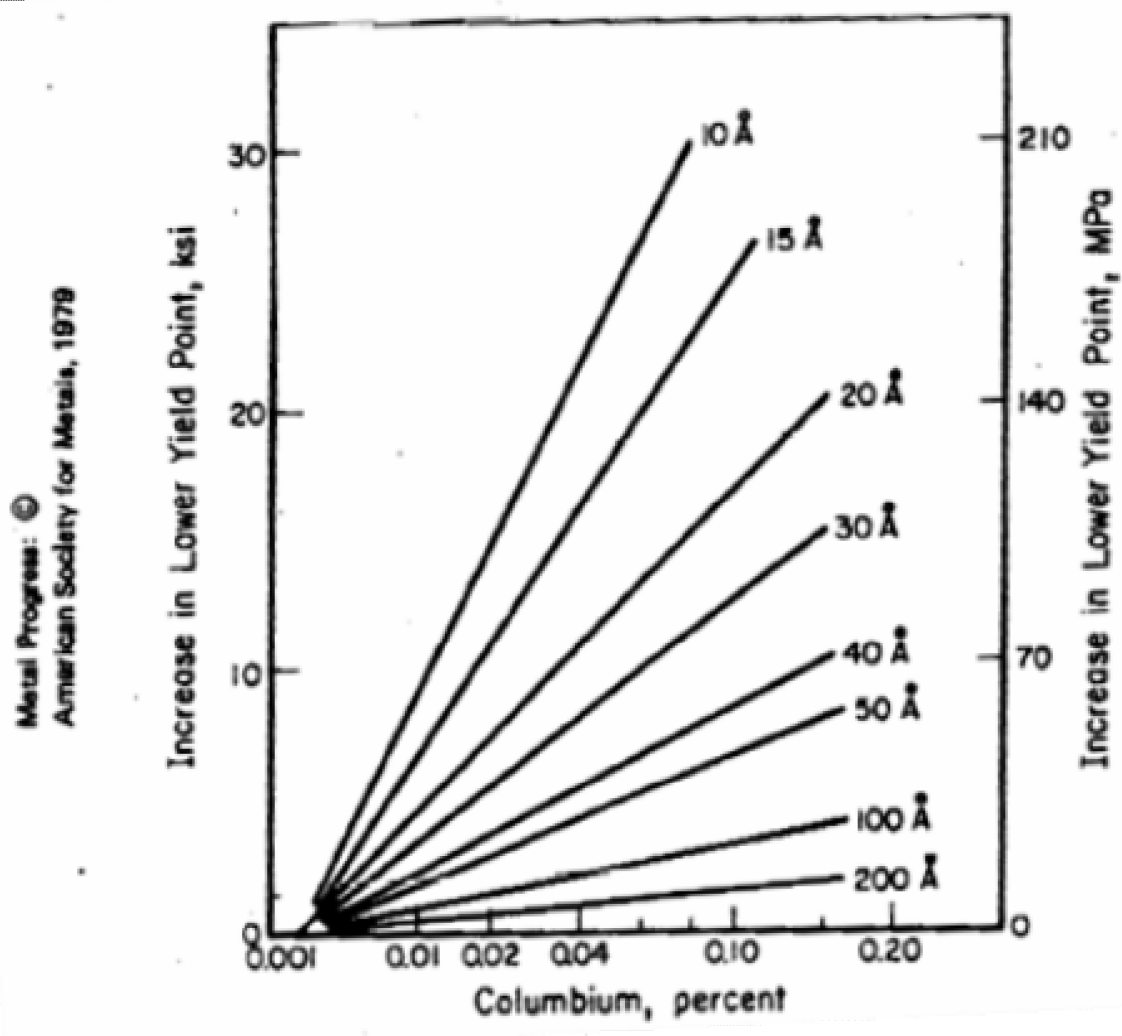

Figure 4 Effect of Precipitate Size on Strengthening HSLA Steels (9) 


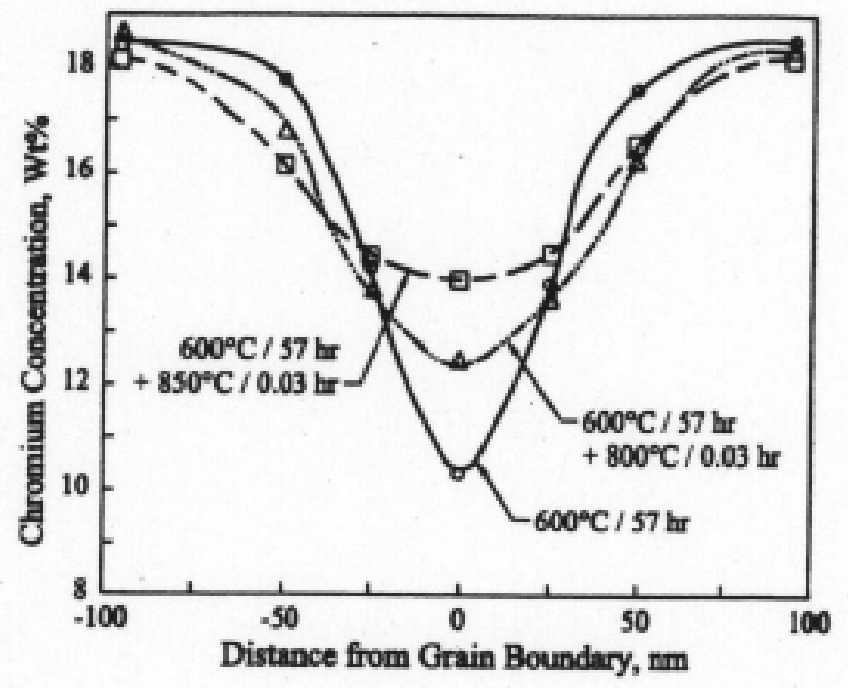

Figure 5 Chromium Depletion Near the Grain Boundaries of Sensitized Steel (10)

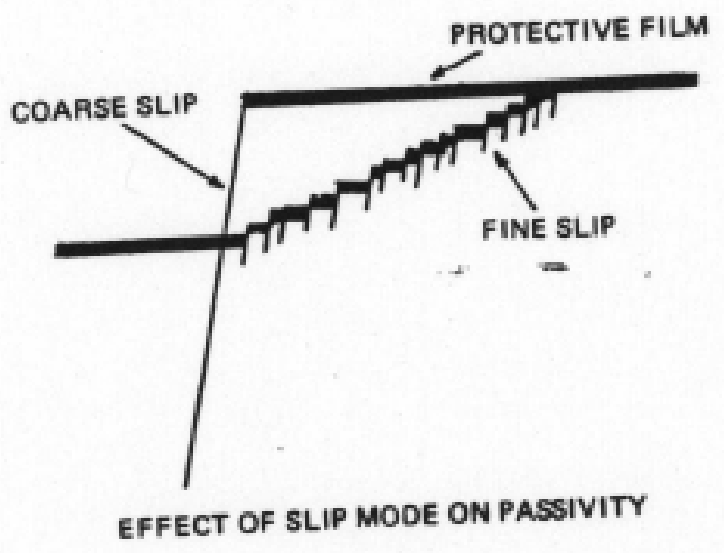

Figure 6 Schematic of Slip Step Emergence and Passive Film Rupture (11) 


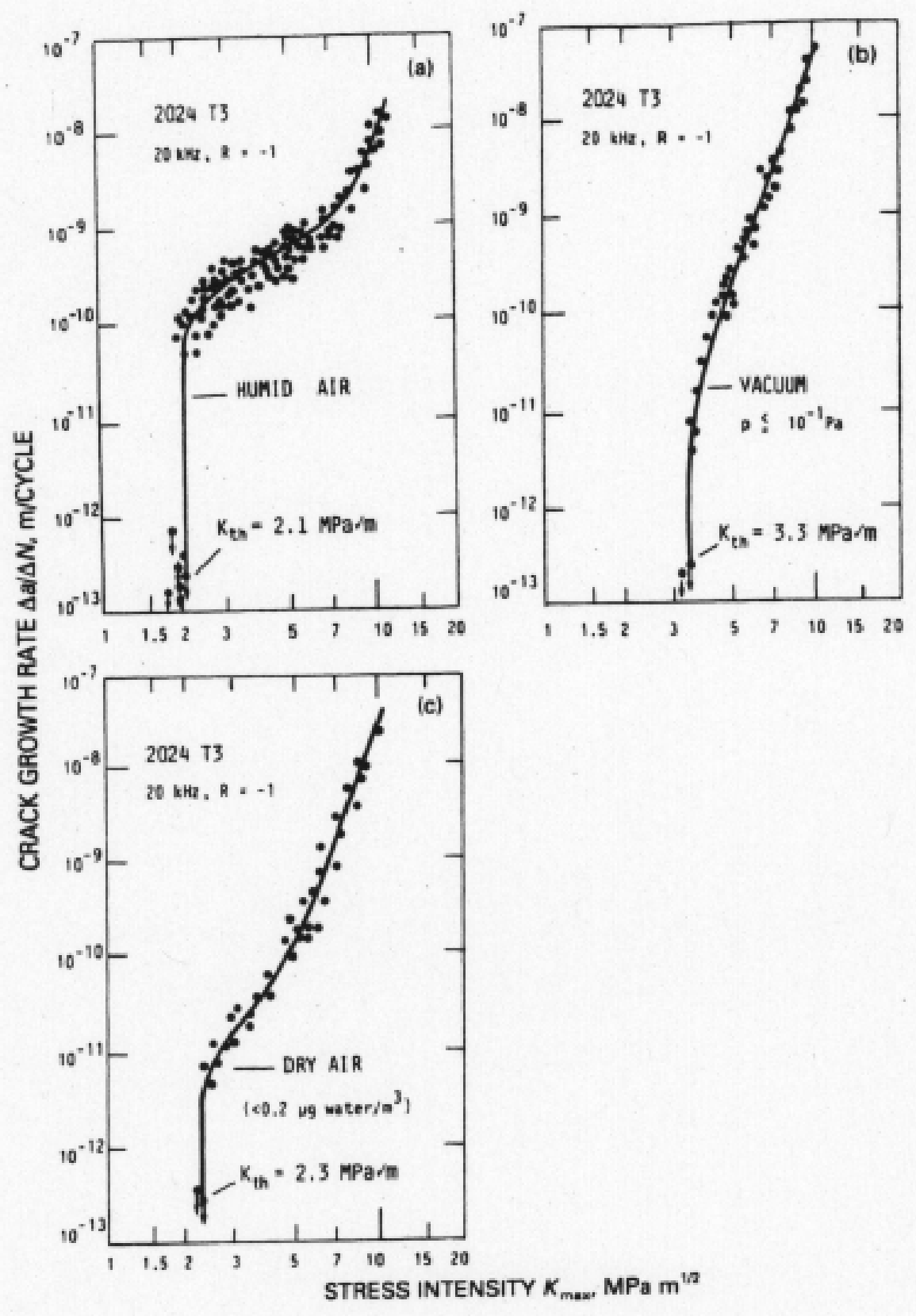

Figure 7 Fatigue Crack Growth in 2024 Aluminum Alloy (12) 
Table 1 Size Effects on the Strength of Carbon Nanotubes (5)

\begin{tabular}{lc}
\hline Length & Strength, GPa \\
\hline $460 \mathrm{~nm}$ & 150 \\
$18 \mu \mathrm{m}$ & 24 \\
$29 \mu \mathrm{m}$ & 28 \\
$60 \mu \mathrm{m}$ & 39 \\
$65 \mu \mathrm{m}$ & 20 \\
$67 \mu \mathrm{m}$ & 35 \\
$69 \mu \mathrm{m}$ & 63 \\
$11.0 \mu \mathrm{m}$ & 21 \\
$1-2 \mathrm{~mm}$ & 36 \\
$2 \mathrm{~mm}$ & 17 \\
&
\end{tabular}

Table 2 Important Strengthening Precipitates in HSLA Steels (9)

\begin{tabular}{ll}
\hline \hline \multicolumn{1}{c}{ Element(s) } & \multicolumn{1}{c}{ Main Precipitates } \\
\hline Columbium & $\mathrm{Cb}(\mathrm{C}, \mathrm{N})^{(\mathrm{a})}, \mathrm{Cb}_{4} \mathrm{C}_{3}$ \\
Vanadium & $\mathrm{V}(\mathrm{C}, \mathrm{N})^{(\mathrm{b})}, \mathrm{V}_{4} \mathrm{C}_{3}$ \\
Columbium + vanadium & $\mathrm{Cb}(\mathrm{C}, \mathrm{N}), \mathrm{V}(\mathrm{C}, \mathrm{N}), \mathrm{Cb}_{4} \mathrm{C}_{3}, \mathrm{~V}_{4} \mathrm{C}_{3}$ \\
Vanadium + nitrogen & $\mathrm{VN}$ \\
Copper & $\mathrm{Cu}$ \\
Copper + columbium & $\mathrm{Cu}, \mathrm{Cb}(\mathrm{C}, \mathrm{N})$ \\
Titanium & $\mathrm{Ti}(\mathrm{C}, \mathrm{N})^{(\mathrm{c})}, \mathrm{TiC}$ \\
Aluminum + nitrogen & $\mathrm{AIN}$ \\
\hline \hline
\end{tabular}

(a) Columbium carbonitride.

(b) Vanadium carbonitride.

(c) Titanium carbonitride. 